\title{
LA TRADUCCIÓN DE LITERATURA ESPAÑOLA EN LA VOZ DE SUS PROTAGONISTAS
}

\author{
por JANA KRÁLOVÁ \\ (Universidad Carolina, Praga)
}

\begin{abstract}
Resumen
Los traductores no sólo crean nuevas palabras o ayudan a la domesticación de expresiones extranjeras, sino que su actividad se realiza también en los niveles más elevados, al introducir en el ambiente receptor nuevos géneros, conceptos, formas poéticas y medios estilísticos. Estudiando la traducción como proceso de comunicación, no se puede prescindir del análisis de la situación personal del traductor y del estudio de sus condiciones de trabajo. Entre otros temas cabe preguntarse cuál fue el motivo que llevó a los escritores a convertirse en una etapa de su vida en traductores y / o viceversa, y en qué medida su obra literaria se vio influida por su labor traductiva y, cómo fueron las condiciones externas en las que desarrollaban su trabajo, etc. El marco teórico de la intervención estará formado por la concepción clásica checa, e incluirá un análisis de las entrevistas con los protagonistas de la traducción literaria de la segunda mitad del siglo XX y de las memorias y autobiografías publicadas recientemente en la República Checa subrayando la importancia de la actividad traductiva, no sólo para las relaciones interculturales entre los respectivos países y comunidades lingüísticas, sino también para el análisis de varios aspectos de la historia de la cultura receptora.

Palabras claves: traductores; historia de la traducción; escritores-traductores; relaciones interculturales; historia de la cultura
\end{abstract}

\begin{abstract}
Translators not only create new words or play a role in the domestication of foreign expressions; they also act at a higher level through the introduction of new genres, concepts, poetic forms and stylistic devices into the target culture. When considering translation as a communication process, the analysis must take into account the translator's working conditions. Among other things it is important to examine the motives writers had to become translators (or vice versa) at some point in their lives, and if and to what extent their literary works were influenced by their translation work, and, last but not least, the external conditions in which their work developed, etc. The theoretical framework of this paper is based on the approach of Czech structuralism and includes an analysis of interviews with the protagonists of literary translation of the second half of the twentieth century as well as a study of the memoires and autobiographies published recently in the Czech Republic. This paper emphasises the importance of translation activity not only for intercultural relationships between the Czech Republic and Spain and their linguistic communities but also for the analysis of various aspects of the target culture's history.
\end{abstract}

Keywords: translators; history of translation; writers-translators; intercultural relationships; cultural history 
Los traductores no sólo crean nuevas palabras o ayudan a la domesticación de expresiones extranjeras, sino que su actividad se realiza también en los niveles más elevados, al introducir en el ambiente receptor nuevos géneros, conceptos, formas poéticas y medios estilísticos. Concibiendo la traducción como un específico proceso de comunicación, no se puede prescindir del estudio de la figura del traductor. Como con razón afirma L. Pegenaute: "de lo que no cabe duda es del papel mediatizador del traductor en este proceso, por cuanto el impacto que una obra traducida tiene en la cultura receptora depende ante todo de la imagen que del texto original construyeron los traductores. Ello viene a significar que los traductores son tan responsables de la influencia de una determinada obra, autor, género o incluso literatura nacional en la cultura receptora, como fueron responsables de ello los autores en la cultura original". ${ }^{1}$ Sin embargo, las condiciones en las que un traductor determinado desarrolla su trabajo, el motivo que llevó a los escritores a convertirse en una etapa de su vida en traductores y / o viceversa, la medida en que su obra literaria se vio influida por su labor traductiva, y las condiciones externas en las que desarrollaba su trabajo representan temas dignos de analizar y van recobrando importancia también en la escala internacional. El motivo radica en que el estudio de la traducción no puede ser considerado sólo como una actividad unilateral que sirve para el enriquecimiento y la transformación de la cultura receptora, sino también como un testimonio de la situación de la cultura meta en una determinada etapa histórica.

A pesar de tratarse de un enfoque relativamente frecuente en la investigación actual en varios ámbitos culturales y lingüísticos, ${ }^{2}$ el marco teórico de este artículo estará formado en primer lugar por

1 Luis PEGENAUTE, "Traducción y recepción”, Trujamán. Revista diaria de traducción, 11-11-1999, accesible de: cvc.cervantes.es/trujaman/anteriores [consultado el 5 de enero de 2016].

2 Cf. por ejemplo José Francisco RUIZ CASANOVA, "La traducción como forma de exilio interior: El caso Marià Manent", : EU-topías, 2013, pp. 113-121; Martina OŽBOT, “The role and status of translation in a translatio-oriented culture: the case of Slovenia,"in: Gerhard Stickel (ed.), Translaslation and Interpretation in Europe. Duisburg Papers on research la concepción clásica checa basada en el estudio de la traducción como un específico proceso de comunicación por parte del traductor tal como fuera definido por el traductólogo checo Jiří Levý, ante todo de su concepción del trabajo del traductor como un continuo proceso de decisiones, realizadas sobre tres niveles de "instrucciones":

1. Instrucciones delimitativas (definición del paradigmas de las lenguas de trabajo), tema que queda al margen del tema del presente estudio.

2. Instrucciones selectivas:

A. El contexto como instrucción objetiva.

$B$. La estructura de la memoria del traductor como instrucción subjetiva, cuya aplicación permite activar los paradigmas subjetivos del traductor y la introducción de este concepto permite explicar la tendencia a la nivelación del estilo.

3. La norma estética como instrucción intersubjetiva que representará el tema central del presente estudio, ${ }^{3}$ ya que pone énfasis en las condiciones externas del trabajo del traductor que la conforman, incluidos sus parámetros temporales y sociales.

Cabe destacar que Levý anticipa esta visión del tema al advertir que la deficiencia de los estudios traductológicos de la época (años cincuenta $\mathrm{y}$ sesenta del siglo $\mathrm{XX}$ ) radica en que no consideran la evolución de la figura del traductor como tal, los cambios de su estilo, destrezas que domina o debe dominar, la opinión que se haya formado sobre la literatura traducida. Del respeto a la figura del traductor deriva otra observación de Jiří Levý: la afirmación de que la decisión primaria, es decir, la elección del texto para traducir es cosa de los editores y pertenece a la llamada sociología de la literatura, tema todavía por definir en la época de la publicación del estudio del traductólogo checo, ${ }^{4}$ pero desarrollado en las últimas décadas por varios investigadores, ante todo en el marco del llamado giro sociológico de la traductología. Aun teniendo presente que la obra de Levý se basa ante todo en la evolución de la historia de las traducciones al checo hasta el año 1945 y deja, por

in Langue and culture, vol. 102, Frankfurt am Main 2013, pp. 139-152.

3 Jana KRÁLOVÁ y Miquel D. CUENCA(eds.), Jiři Levý: una concepción (re)descubierta, Vertere, Monográficos de Herméneus, Soria, 2013, p. 33.

4 Ibidem. 
varios motivos, de lado la situación que se produjo en el país después de la II Guerra Mundial, se hace patente que su concepción, considerada no como una afirmación categórica sino como cierto marco teórico, no ha perdido su vigencia metodológica para la investigación actual. La vigencia general de su concepción se ve corroborada por ejemplo por la opinión de Ruiz Casanova, quien afirma refiriéndose al caso español: "La Historia de la Traducción en España debe tanto a las aportaciones que, por la vía comercial o por la vía estética, han realizado sus autores como a determinadas situaciones históricas, sociológicas o morales, que han determinado, para bien o para mal, la publicación -o no- de algunas obras." 5

El análisis de la importancia de los parámetros socio-culturales de las traducciones publicadas en cierta época aparece en la obra de varios especialistas en diversas comunidades lingüísticas y culturales, siendo el tema de la censura uno de los privilegiados, ampliamente desarrollado por los investigadores españoles e incipiente en el ámbito checo. ${ }^{6}$

Volviendo al tema del traductor como mediatizador, por una parte, y como persona de carne y hueso, no se puede prescindir de la situación cultural y social de la época en que desarrolló sus actividades. En el área de las literaturas hispánicas disponemos, además de la historia de la traducción escrita por Miloslav Uličný ${ }^{7}$ y del reciente libro de Jaroslava Kašparová, ${ }^{8}$ de importantísimas fuentes directas: las entrevistas con veintisiete fundadores de la traducción literaria de la época de posguerra, nacidos ente los años 1920 y 1935 , entre ellos, los hispanistas Josef Forbelský(*1930), Vladimír Mikeš (*1927) y Antonín Přidal (*1935), ${ }^{9}$ y la autobiografía del tal vez más destacado de ellos,

5 J. F. RUIZ CASANOVA, "La traducción", p. 113.

6 Grupo TRACE, publicaciones accesibles en http://hdl.handle.net/10810/10169, J. ŠPIRK, Censorship, Indirect Translation and Non-Translation, Newcastle, 2014.

7 Miloslav ULIČNÝ, Breve historia de traducciones checas de obras de autores de España e Hispanoamérica (1838-1998), Praha 2005.

8 Jaroslava KAŠPAROVÁ, Amadís Waleský nebo Don Quijote? [¿Amadís de Gaula o Don Quijote?], Praha 2015.

9 Stanislav RUBÁŠ (ed.), Slovo za slovem [Palabra por palabra] Praha 2012.
Josef Forbelský.${ }^{10}$ Las obsevaciones que siguen se basarán ante todo en sus testimonios.

El camino de los fundadores de la traducción literaria de la segunda mitad del sigo XX hacia el español y las literaturas hispánicas no fue directo ni fácil. Como afirma Antonín Přidal, "el español fue mi segunda titulación, pues tuve que escribir dos memorias de licenciatura, no sólo una como mis colegas. Mi objetivo fue evitar la docencia, profesión obligatoria para el $95 \%$ de los graduados de la época. Con el español no fue posible, es que no había institutos donde se enseñara". ${ }^{11}$ Una de sus primeras traducciones del español fue El libro de buen amor de Juan Ruiz, una traducción dificílisima para un estudiante de un poco más de veinte años. Recuerda que "el doctor Bělič conocía al anglista Jiří Levý, quien venía a Brno de Olomouc para dar clases, y me dijo que Levý había intentado traducir varias canciones del Libro de buen amor, porque le interesaba su estructura, pues podría enseñarle mi método. Así que empecé a enviar las muestras de la traducción a los dos, y Jiř́ Levý no tardó en invitarme a su casa en Brno. Fue un hombre muy amable, sólo nueve años mayor que yo. Los consejos que me daba fueron breves y exactísimos [...]. Desde luego me recomendó que no dejara de concentrarme en la traducción de Ruiz y no tardara en terminarlo. Tenía razón: miles de versos del siglo XIV representaban un laberinto para un estudiante de veintiún años. Cuanto más iba trabajando, podían ser sólo unas horas semanales, tanto más me fui dando cuenta de que no podía entregar el libro a tiempo. Cuando me gradué, en 1958, no había terminado ni la mitad y me esperaban 18 meses del servicio militar obligatorio."

Los motivos que llevaron a esta generación de traductores al realizar su trabajo fueron diferentes, en varios casos económicos, pero también relacionados con la situación social y cultural de la época. Un résumen muy claro de la situación aparece en la entrevista con Josef Forbelský: "Traducía para consolar mi alma. En su época fue no solo un espacio intelectual para mi generación, sino también para la generación anterior. Cuando se traduce un texto interesante, cada traducción tiene su valor. Es también un diálogo precioso con espíritus y culturas excepcionales. Sin embargo, lo que me

10 Josef FORBELSKÝ, Svět se mnou, svět beze mne [El mundo conmigo, el mundo sin mí], Praha 2013.

11 RUBÁŠ, (ed.), Slovo, pp. 333-333. 
llevó a traducir fue también la situación en que se encontraba la cultura checa. Para mi generación fue la ruptura del contacto con los países occidentales (negrita J. K.). No fue un simple interés por el Occidente, sino la conciencia de que Europa estaba dividida y de que la ebullición cultural y el intercambio cultural, en que se basaba Europa, se había interrumpido." 12

He aquí otra coincidencia con lo que advierte Ruiz Casanova:"13 "Historia de la Traducción, Historia de exilios", tal vez podamos decir de evasiones ante el aislamiento cultural de los intelectuales y de toda la sociedad en una determinada etapa de su evolución histórica.

Desde luego, el traductor no vive en el vacío y en la traducción de una obra no puede desvincularse de su situación personal y familiar. Josef Forbelský nos deja una constancia de este fenómeno en su autobiografía: "al fin y al cabo, el trabajo en la traducción de los ensayos impresionistas de Azorín (1873-1967), en original Los pueblos, se convirtió para mí en un diálogo con «lo que ha dejado de existir». La editorial Odeon incluyó el libro en la serie Světová četba [Letras Universales] escogiendo un título más atractivo para el público checo: Pod španělským sluncem [Bajo el sol de España - 1982]. Para expresar la estética del autor del original hubo que buscar en checo las palabras capaces de representar las impresiones y estados de ánimo. El ritmo, basado en los versos, llegó a ser más moderado, y las impresiones se basaban más en los adjetivos." 14

El ambiente cultural de la época (1948-1989), que se reflejaba también en el área de la traducción literaria, se vio marcado por varias peculiaridades. Todos los libros publicados tuvieron que ser aprobados por el Ministerio de Cultura, hasta mediados de los años sesenta existió oficialmente la censura, sustituida después por la autocensura, en algunos aspectos más nefasta para la actividad editorial. Había personas que por motivos políticos no podían colaborar con las editoriales y para poder traducir tenían que realizar su profesión "bajo cuerda", es decir, bajo el nombre de algún colega, procedimiento tácito, basado en la confianza entre los participantes. Josef Forbelský dice al respecto: "El problema fue que varias personas estaban privadas de su identidad, las autoridades no permitían

12 RUBÁŠ, Slovo, p. 85.

13 RUIZ CASANOVA, "La traducción", p. 113.

14 FORBELSKÝ, Svět, p. 402. publicar sus nombres y permitían nombres que no importaban, no molestaban. Para citar un ejemplo, cuando Lumír Čivrný (uno de los fundadores del hispanismo checo de los años sesenta - nota J. K.) intentaba traducir a Juan Ramón Jiménez, no querían permitírselo y alguien debía encubrirlo. Pero él se sintió ofendido y dijo: "Pues yo presté mi nombre a una persona ejecutada durante la II Guerra Mundial, y ahora ¿debo esconderme?” Había diferencias: a algunos les convenía ser encubiertos, otros se sentían humillados. El encubrimiento se consideraba un deber, hasta los que desempeñaban los cargos oficiales se vieron obligados a hacerse los de la vista gorda. Muchas veces sabían que el que firmaba no hacía el trabajo, pero no dijeron nada."15

Antonín Přidal, otro traductor importante, fue el que vivió esa situación durante algún tiempo en su propia carne: "El traductor que podía publicar sus obras bajo su nombre tenía una seguridad relativa de tener trabajo y de poder influir los planes de las editoriales con sus propuestas. Claro, la situación política de la época conllevaba el riesgo de que algunos autores extranjeros podían ser prohibidos de un día para otro, o simplemente excluidos de los planes editoriales. El traductor que trabajaba bajo cuerda se veía atemorizado. Cuando una editorial cambiaba los planes y hacía desaparecer los títulos con que contaba, no sabía si tendría trabajo en los próximos meses. No podía ofrecer proyectos, negociar con los jefes ni dirigirse a la editoral oficalmente. Tenía las manos atadas. Trabajar como traductor callado significaba ser un ghost writer, privado de todos los derechos, que tiene que apostar en que siga habiendo gente decente que le ayude. Fue humillante ya por tener que prescindir del nombre propio, por no poder decir esta obra es mía."16

Tal vez este fuera el motivo por el cual impulsó la revelación de los traductores reales de las obras: "Cuando en el año 1990 empezó a trabajar la Comunidad de Traductores, propuse que no tardara en hacerse algo con las traducciones, cuyos autores tuvieron que ser callados, es decir, que se publicara una bibliografía que lo corrigiera. Que los encubridores confirmaran lo que habían encubierto, y los ocultus que hicieran una lista de lo que no pudieron publicar bajo su nombre. Insistí en que se hiciera cuanto antes porque tenía claro que una vez desarrolladas nuevas actividades en la nueva sociedad, ya no habrá quien lo haga.

\footnotetext{
15 RUBÁŠ, Slovo, p. 89.

16 Ibidem, pp. 342-343.
} 
Además, muchos de los afectados ya eran de edades muy avanzadas. Las 690 entradas, que hemos reunido en el libro Zamlčovaní překladatelé [Los traductores callados], es un número elevado y no creo que falten más de diez o veinte títulos." ${ }^{17}$

Como ya se ha señalado, las prohibiciones de publicación no afectaban solamente a los traductores y escritores domésticos, había autores extranjeros cuyos libros no podían ser publicados. De entre las literaturas hispánicas cabe citar como ejemplo a Octavio Paz: después de que firmara la declaración en contra de la ocupación de Checoslovaquia por los ejércitos del Pacto de Varsovia, la traducción de sus ensayos El arco y la lira no sólo fue prohibida, sino que los libros ya impresos fueron destruidos.

Había intervenciones directas también en los textos de las traducciones, de las cuales no se salvaban ni los clásicos. Otro traductor, Vladimír Mikeš, recuerda " $[\ldots]$ en la obra de Calderón $L a$ vida es sueño aparece la frase « ¡La libertad y el rey vivan!». Y de repente, en el teatro E. F. Burian dicen que hay que tacharla, porque el público empezó a aplaudir al oírla. Los responsables se espantaron y hubo que eliminarlo. La autocensura funcionaba." 18

De la situación mencionada partía la función especial que cumplían los peritextos: los prólogos y los epílogos de los libros traducidos. Josef Forbelský afirma al respecto: "Después de la revolución (1989) llegaron mis estudiantes y me dijeron: «Vamos a publicar sus prólogos y epílogos». Y yo les dije: «Ni pensarlo». Es que los prólogos y epílogos solían escribirse ante todo para que el texto pueda pasar, es decir su función era sometida a un clima político determinado. El régimen los tomaba como parte de la formación: «El autor del libro puede ser dudoso, pero el autor del epílogo se lo aclarará». Era una estrategia que se aplicaba no sólo en la época del comunismo, por ejemplo JaroslavVrchlický (poeta y traductor checo de las últimas décadas del siglo XIX y de las primeras del XX - nota J. K.) solía escribir el epílogo para hacer pasar el libro. Pero desde luego hay excepciones: varios epílogos son excelentes estudios y se podrían publicar también en nuestros tiempos." 19

17 Ibidem, p. 340.

18 Ibidem, p. 257.

19 RUBÁŠ, Slovo, p. 93.
Los testimonios de los traductores que acabamos de presentar no sólo corroboran la importancia cultural de dicha profesión, destacando, como Pegenaute "el papel mediatizador del traductor [...], por cuanto el impacto que una obra traducida tiene en la cultura receptora depende ante todo de la imagen que del texto original construyeron los traductores. Ello viene a significar que los traductores son tan responsables de la influencia de una determinada obra, autor, género o incluso literatura nacional en la cultura receptora, como responsables fueron de ello los autores en la cultura original", ${ }^{20}$ sino que subrayan la importancia del estudio de la actividad traductiva para conocer la historia cultural de un país en una época determinada conforme a la opinión de Ruiz Casanova de que "la Historia de la Traducción (no sólo - enmienda J. K.) en España debe tanto a las aportaciones que, por la vía comercial o por la vía estética, ha realizado sus autores como a determinadas situaciones históricas, sociológicas o morales, que han determinado, para bien o para mal, la publicación -o no- de algunas obras." ${ }^{21}$ Es decir, considerarlas condiciones que influían en la elección de la obra para traducir y publicar y las condiciones externas del trabajo del traductor. Las opiniones y experiencias de los protagonistas de la actividad traductiva en el área de las letras hispánicas contribuyen, junto con otros trabajos realizados, a profundizar no sólo la historia de hispanismo checo y de las relaciones checo-españolas, sino también la historia cultural de nuestro país.

(Escrito en español por la autora)

\section{BIBLIOGRAFÍA}

FORBELSKÝ, Josef, Svět se mnou, svět beze mne [El mundo conmigo, el mundo sin mí], Praha: Academia, 2013.

KAŠPAROVÁ, Jaroslava, Amadís Waleský nebo Don Quijote? [¿Amadís de Gaula o Don Quijote?], Praha: Veduta, 2015.

KRÁLOVÁ, Jana - CUENCA, Miguel, Jiři Levý: una concepción (re)descubierta, Soria: Vertere. Monográficos de la revista Herméneus, 2013.

\footnotetext{
20 PEGENAUTE, “Traducción”, op. cit.

${ }^{21}$ RUIZ CASANOVA, “La traducción”, p. 116.
} 
OŽBOT, Martina, "The role and status of translation in a traslantio-oriented culture: the case of Slovenia," in: Gerhard Stickel (ed.), Translaslation and Interpretation in Europe. Duisburg Papers on research in Langue and cultu$r e$, vol. 102, Frankfurt am Main: Peter Lang, 2014, pp. 139-152.

PEGENAUTE, Luis, "Traducción y recepción”, Trujamán. Revista diaria de traducción, Accesible de 11-11-1999, cvc.cervantes.es/trujaman /anteriores, [consultado el 5 de enero de 2016]. RUBÁŠ, Stanislav (ed.), Slovo za slovem [Palabra por palabra], Praha: Academia, 2012.
RUIZ CASANOVA, José Francisco, "La traducción como forma de exilio interior: El caso Marià Manent", EU-topías, Universtitad de València-Universitè de Genève, 2013, pp. 113-121

ŠPIRK, Jaroslav, Censorship, Indirect Translation and Non-Translation, Newcastle: Cambridge Scholars Publishing, 2014

ULIČNÝ, Miloslav, Breve historia de traducciones checas de obras de autores de España e Hispanoamérica (1838-1998), Praga: Editorial Karolinum, 2005. 